\title{
Süt Sığırı Ahırlarının Modernizasyonunda Sera Tipi Ahırların Maliyet Yönünden Araştırılması
}

\author{
Görkem Yılmaz' \\ Ünal Kızıl ${ }^{*}$ \\ ${ }^{1}$ Çanakkale Onsekiz Mart Üniversitesi, Fen Bilimleri Enstitüsü, Tarımsal Yapılar ve Sulama Anabilim Dalı, Çanakkale \\ ${ }^{2}$ Çanakkale Onsekiz Mart Üniversitesi, Ziraat Fakültesi, Tarımsal Yapılar ve Sulama Bölümü, Çanakkale \\ *Sorumlu yazar: unal@comu.edu.tr \\ ${ }^{1}$ https://orcid.org/0000-0001-9995-2818, ${ }^{2}$ https://orcid.org/0000-0002-4132-5931
}

Geliş Tarihi: 07.08.2019

Kabul Tarihi: 05.11.2019

\section{$\ddot{\mathbf{O z}}$}

Süt sığırı işletmelerinin verimliliklerinin artırılması amacıyla modernizasyon yapılması ve alternatif ekonomik yapı sistemlerinin hayvan barınağı olarak kullanılma potansiyellerinin araştırılması gerekmektedir. Bu çalışmanın amacı, ülkemizde hayvancılığın yoğun olarak yapıldığı bölgelerden biri olan Çanakkale İli, Biga İlçesindeki küçük bir süt sığırı işletmesinde barınaklardaki yapısal sorunları dikkate alınarak mevcut ahırlara alternatif bir sistem önermek ve süt sığırı işletmelerinin modernizasyonuna ilişkin bir model ortaya koymaktır. Çalışma sonucunda çelik konstrüksiyon sundurma tipi ve sera tipi olmak üzere 2 farklı yeni sağmal ahır alternatif olarak projelenmiş ve maliyet analizleri yapılmıştır. Araştırma sonuçlarına göre barınakların modernize edilmesi yeniden inşa edilmesine göre yaklaşık \%50 daha ekonomik olduğu bulunmuştur. Ayrıca sağmal hayvan başına düşen maliyet geleneksel çelik konstrüksiyon sistemde 1,394.75 \$, sera tipi ahırda ise 1,221.64 \$ olarak belirlenmiştir. Bu çalışmada sera tipi sistemin toplam maliyeti ancak \%13 kadar düşürdüğü görülmüştür. Bölge koşullarında yaygın olarak kullanılması konusunda tavsiye edilebilmesi için daha fazla çalışmaya ihtiyaç duyulmaktadır.

Anahtar Kelimeler: Süt sığırı ahırı, modernizasyon, çelik konstrüksiyon, sera tipi ahır

\section{A Case-study on Cost of Greenhouse Barns in Modernization of Dairy Barns Abstract}

In order to increase the efficiency of dairy farms, modernization should be done and potential economic structure systems should be investigated as livestock barn. The aim of this study is to propose an alternative system to the existing barns and to present a model for the modernization of dairy enterprises by considering the structural problems in the barns in a small dairy farm in the Biga District of Çanakkale, which is one of the regions where animal husbandry is the most intensive in Turkey. As a result of the study, two different dairy barns, steel shed type and greenhouse type, were designed as an alternative and cost analysis was performed. According to research results, modernization of barns is about 50\% more economical than reconstruction. In addition, the cost per milking animal was determined as $\$ 1,394.75$ in the traditional steel construction system and $\$ 1,221.64$ in the greenhouse type barn. In this study, it was observed that the total cost of the greenhouse system was reduced by only $13 \%$. Therefore, further studies are needed to be recommended.

Keywords: Dairy barn, modernizastion, steel construction, greenhouse barn

\section{Giriş}

Dünyanın çoğu bölgesinde evcil hayvanların optimum iklim isteklerini sürekli olarak sağlamak mümkün değildir. Doğadaki vahşi hayvanlar göç ederek kendileri için optimum iklim koşullarının bulunduğu bölgelere gidebilmektedirler. Ancak, evcilleştirilmiş hayvanların bu olanakları mevcut değildir. Dolayısıyla, evciltilmiş hayvanların en uygun çevresel koşulları sağlayacak barınaklarda barındırılması gereksinimini ortaya çıkmıştır. Çünkü, dünyada çoğu iklim bölgesinde hayvanların yıl boyu çevresel isteklerini karşılamak mümkün değildir (Kızıl ve ark., 1998).

Hayvanların çevresel koşullara karşı verdikleri tepkilerin fizyolojik ve biyolojik esasları ile çevresel koşulların (sıcaklık, nem vb.) hayvan 1sı üretim ve kayıplarına etkisi gibi konuların araştırılması gerekir. Hayvanların fizyolojik özellikleri ve mevcut iklim koşulları hakkında yeterli bilgiye sahip olunduktan sonra hayvan genetik istekleri doğrultusunda ve aynı zamanda ekonomik yetiştiriciliğe uygun çevresel koşullar sağlanabilir (Esmay, 1978).

Ülkemizde süt sığırı işletmelerinin çok büyük bir kısmı 50'den az sağmal hayvana sahip küçük aile işletmeleridir (Uzundumlu, 2012). Bu işletmelerin nerdeyse tamamında havalandırma ile 
ilgili sorunlar vardır. Doğal havalandırma sistemleri ya hiç yok ya da yetersizdir. Benzer şekilde mekanik havalandırma ve serinletme sistemleri de yok denecek kadar azdır. İklimlendirmede yaşanan bu yetersizliklerden dolayı çok büyük verim kayıpları söz konusu olmaktadır (Özdemir, 2007).

Hayvan barınaklarında ve özellikle de süt sığırı ahırlarında görülen diğer bir problem de barınakların ve diğer tesislerin inşaatlarının gelişigüzel yapılması, bir projeye dayanmaması ve genelde taklit şeklinde inşa edilmeleridir. Bu ise, hem yapının yukarda açıklanan çevre denetimiyle ilgili koşulları sağlamamasına, hem işletmeciliği zor hale getirecek başarısız sistemlerin ortaya çıkmasına hem de çoğu zaman inşaat maliyetlerinin gereğinden fazla olmasına neden olmaktadır. Tarımsal yapılardan beklenen en önemli fonksiyonların başında, işlevselliğinden tavizde bulunmadan mümkün olduğu kadar düşük maliyetli sistemlerin projelendirilmesidir (Olgun, 2016). Ancak yukarda da açıklandığı üzere hiç projelendirilmemiş ya da taklit projelerle bunu sağlamak mümkün değildir.

Süt sığırcılı̆̆ yetiştiriciliğindeki yeni yaklaşımlar ve teknolojik değişiklikler, yeni barınaklarda üretim yapmaya zorlamaktadır. Alternatif olarak da mevcut bina ve makinelerin modernize edilmesi karşımıza çıkmaktadır. Bu bağlamda yapılacak modernizasyon çalışmaları ve yeni teknolojilerin uygulanması, iş yükünü önemli ölçüde azaltacağı gibi süt sığırlarının verimini de artıracaktır. $\mathrm{Bu}$, inek refahında bir iyileşme ve süt üretiminin maliyet etkinliğinin artması ile ilişkilendirilmiştir (Herbut ve ark., 2017).

Bir çalışmalarında Yaslıoğlu ve ark. (2008) Bursa ilinde iki adet bağlı duraklı ahırın serbest duraklı sisteme dönüşüm maliyet ve olanaklarını tartışmışladır. Çalışma sonucunda ahırların modernizasyonu için 1 ve 2 nolu işletmelerde sırasıyla 25.060 ve 4.993 \$ maliyet hesaplamışlardır. Araştırmacılar modernize edilmiş barınakların hayvan refahı ve işgücü tasarrufu açısından daha uygun hale getirildiklerini belirtmişlerdir. Ancak, işletmelerin modernize edilebilir nitelikte olması gerektiğini vurgulamışlardır.

Horne ve Prins (2002) Hollanda ve Avrupa Birliği yasalarının çoğu zaman eski barınakların modernizasyonu ile ilgili olarak teşvik edici olduklarını belirtmişlerdir. Hollanda'daki modernizasyon sürecinin tarihçesinin anlatıldığı çalışmada elde edilen faydalar özetlenmiştir. Gerek hayvan sağlığı ve refahı gerekse süt veriminin artırılması açısından hem yapısal olarak hem de mekanizasyon anlamında modernizasyonun önemine vurgu yapılmıştır.

Bazı durumlarda modernizasyon çalışmaları kapsamında yeni bir barınak yapma gereksinimi de ortaya çıkabilmektedir. Dolayısıyla alternatif barınak sistemlerinin de bu bağlamda dikkate alınması gerekmektedir. Tarımsal amaçlı yapılarda kullanılabilecek alternatif sistemlerle ilgili arayışlar devam etmektedir. Bu amaçla kullanılan bir sistem de sera tipi barınaklardır (Woodbury ve ark., 2002; Moody ve ark., 2006).

Sera tipi ahırlar, hayvancılık için çok yönlü ve düşük maliyetli bir alternatif sunmaktadır (Honeyman, 2005). Bu yapı tarzının esası çelik borudan üretilmiş ve kolonlara tutturulmuş kemerlerin UV dirençli polivinil muşamba ile kaplanmasıdır. Bu tür barınaklar ilk olarak 1990'ların başlarında Kanada'da geliştirilmiştir (Connor, 1993) ve öncelikle domuz barınağ 1 olarak kullanılmıştır (Honeyman ve ark., 2001). Honeyman ve ark. (2008) bu yapı tarzını besi sığırcılı̆̆ında kullanmış ve yazın çevre koşullarının kontrolü ve hayvanların üzeri kapalı bir ortamda barındırılmasından dolayı kirlenmiş yüzey akışının azalması gibi konularda avantaj sağladığını ortaya koymuştur.

Doran ve ark. (2010) yaptıkları bir çalışmada 15 tek-eğimli (mono-slope) ve 14 sera tipi yapı sistemindeki toplam 29 adet barınağın yapısal performanslarını araştırmışlardır. Çalışma sonuçlarına göre üzere bazı konularda tek-eğimli barınaklar bazılarında ise sera tipi yapı sistemindeki barınaklar avantaj sağlamışlardır. Ancak yine aynı araştırmacılar toplam 29 işletmenin incelenmesiyle elde edilen sonuçların çok bağlayıcı olmayacağı ve işletmenin işletmecilik yeteneklerinin bu sonuçlar üzerinde etkili olabileceğini belirtmişlerdir.

Sera tipi bir barınak sisteminin başlıca unsurları aşağıda gösterilmiştir (Kammel, 2004). Bu çalışmada 10 sağmal hayvana sahip bir süt sığırı işletmesinin modernizasyon çalışması kapsamında sera tipi ahırın kullanılması durumunda toplam maliyetin ne kadar değişeceği araştırılmış ve çelik konstrüksiyon sundurma tipi serbest ahırla maliyetler karşılaştırılmış ve önerilerde bulunulmuştur. Ayrıca, süt sığırcılığının çok önemli bir tarımsal üretim faaliyeti olduğu Çanakkale İli, Biga ilçesi için sera tipi ahırların uygunluğu tartışılmıştır. 


\section{Materyal ve Yöntem}

Bu çalışmada Çanakkale İli Biga İlçesi, Çeşmealtı Köyünde bulunan küçük aile işletmesi şeklinde faaliyetlerine devam eden bir işletmedeki süt sığırı barınağı ele alınmıştır. Çalışmaya konu olan işletmenin konumu da Şekil 1'de verilmiştir. Mevcut halinde 10 sağmal hayvana sahip işletme kapasitesini artırmak istemektedir. Bu bağlamda halen hayvanların gezinti alanı olarak kullandıkları yaklaşık $1600 \mathrm{~m}^{2}$ 'lik bitişik arazisine yeni bir ahır yapmak istemektedir. Mevcut binalar ise ya farklı amaçlarla kullanılacak ya da kapasiteleri değiştirilecek şekilde modernize edilecektir. Yılmaz ve Kızıl (2018) işletmenin çelik konstrüksiyon geleneksel sundurma tipi serbest sistem ahır ile yapılmış olan modernizasyon çalışmalarının mimari özelliklerini ortaya koymuştur. Bu çalışmada ise modernizasyon çalışmalarının maliyeti ve çelik konstrüksiyon sundurma tipi ahıra alternatif olarak da sera tipi ahırın uygulanması durumunda toplam modernizasyon ve inşaat maliyetlerinin nasıl etkileneceği ortaya konmuştur.

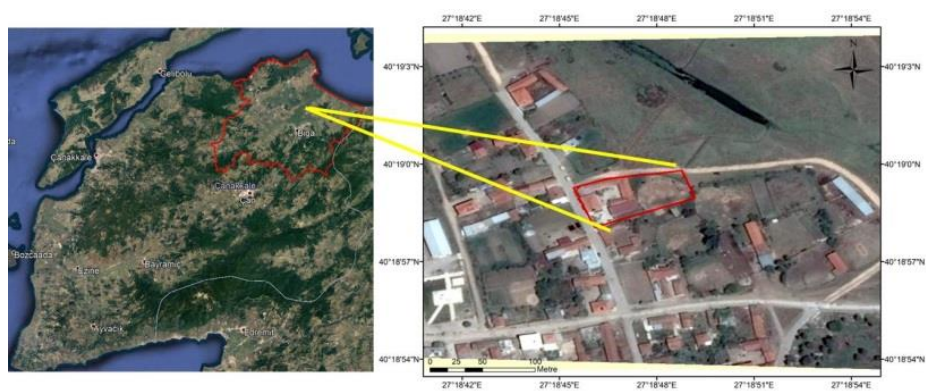

Şekil 1. Çalışma alanı ve işletme

\section{Bulgular ve Tartışma}

Modernizasyon projesi kapsamında bazı ünitelerin kullanım amacı bazılarının ise boyutsal özellikleri değiştirilmiştir. Bu bölümde modernizasyon projesi kapsamında yapılmış olan değişiklikler ve kapasite hesapları üzerinde durulacak, yapılan değişikliklerin gerekçeleri açıklanacaktır. İşletmenin modernizasyon öncesi ve sonrası yerleşim planları Şekil 2'de gösterilmiştir.

Sağımhane ve Süt Odası: İşletmede modernizasyon önceki durumda hem sağımhane hem de sağmal ahır olarak kullanılan kısım modernizasyon ile birlikte sadece sağımhane olarak planlanmıştır. Yeni yapılacak sağmal ahırın kapasitesi 20 baş olacaktır. Bu bağlamda sağımhane tek sıralı ve $1.2 \mathrm{~m} \times$ $2.4 \mathrm{~m}$ boyutlarında 8 adet sağım durağına sahip olacak şekilde modernize edilmiştir. Bu kısımda daha önceden bulunan $80 \mathrm{~cm} \times 90 \mathrm{~cm}$ boyutlarındaki toplam 3 adet havalandırma penceresi sayıs1 5'e çıkarılmış, boyutları da $100 \mathrm{~cm} \times 100 \mathrm{~cm}$ olacak şekilde artırılmıştır. Bu şekilde taban alanının yaklaşık 1/15'i kadar yani toplam $5 \mathrm{~m}^{2}$ 'lik bir pencere alanı sağlanmıştır (Olgun, 2016). Ayrıca, çatıda bulunan havalandırma bacası iptal edilerek, çatıda mahya boyunca $15 \mathrm{~cm}$ genişliğinde sürekli havalandırma açıklığı bırakılarak doğal havalandırma etkinliği artırılmıştır.

Sağımhane ile birlikte bir süt odası da planlanmıştır. Bunun için sağımhanenin bitişiğinde bulunan genç hayvan ahırının bir kısmı $\left(3.8 \times 7=26.6 \mathrm{~m}^{2}\right)$ süt odası olarak yeniden projelendirilmiştir. Olgun (2016) 25 sağmala kadar işletmelerde süt odası için $22.5 \mathrm{~m}^{2}$ lik alanın yeterli olacağını belirtmiştir. Dolayısıyla ayrılan alanın yeterli olduğu görülmektedir. Sağımhane ve süt odasında hijyeni sağlayabilmek adına duvarların beyaz fayansla kaplanması öngörülmüştür.

Doğum Bölmesi: Modernizasyon öncesi genç hayvan ahırı olarak kullanılan $60.2 \mathrm{~m}^{2}$ 'lik bölümün bir kısmı $\left(26.6 \mathrm{~m}^{2}\right)$ yukarda açıklandığı üzere süt odası olarak kullanılacaktır. Geri kalan 33.6 $\mathrm{m}^{2}$ 'lik alan ise doğum bölmesi olarak değerlendirilecektir. Böylece işletmede hem doğum bölmesi, hem de hasta hayvan bölmesi olacaktır. Olgun (2016) doğum bölmesi için ayrılacak alanın her 20-25 hayvan için tercihen $16 \mathrm{~m}^{2}$ olmasını önermiştir. Dolayısıyla işletmede modernizasyon sonrası yeterli büyüklükte bir doğum bölmesi olacaktır.

Buzağı Ahırı: Mevcut halinde $40 \mathrm{~m}^{22}$ lik bir alana sahip olan buzağı ahırında buzağılar gruplandırılmadan yetersiz çevresel ve hijyenik koşullar altında barındırılmaktadır. Ayrıca işletmenin modernizasyon sonrası sahip olacağı kapasite için de yeterli bir alan mevcut değildir. Bu bağlamda mevcut buzağı ahırının bitişiğinde bulunan depodan $24.2 \mathrm{~m}^{2}$ lik bir alan aradaki duvar yıkılarak buzağ1 ahırına dahil edilecektir. Böylece buzağı ahırının alanı $57.3 \mathrm{~m}^{2}$,ye çıkarılmış olacaktır. Modernize edilecek buzağı ahırında $0-2$ ay arası buzağılar için 6 adet $1 \mathrm{~m} \times 2 \mathrm{~m}$ boyutlarında bireysel 
bölme ve 2-3 ay arası buzağılar için ise $2.30 \mathrm{~m} \times 6.75 \mathrm{~m}=15.3 \mathrm{~m}^{2}$ lik grup bölmesi düşünülmüştür. Olgun (2016) bireysel buzağı bölmelerinin genişliklerinin 80-100 cm, uzunluklarının ise $125-210 \mathrm{~cm}$ arasında olması gerektiğini önermiştir. Yine aynı kaynakta 3 aya kadar olan buzağılar için grup bölmelerinde buzağı başına bırakılması gereken alanın $1.5 \mathrm{~m}^{2}$ olması gerektiği belirtilmiştir. $\mathrm{Bu}$ bağlamda 2-3 ay arası 10 buzağı için gerekli alanın $15 \mathrm{~m}^{2}$ olması gerektiği, modernizasyon projesinde de bu değerin $15.3 \mathrm{~m}^{2}$ olduğu görülmektedir. Modernize edilmiş buzağı ahırında hijyen amaçlı duvarların beyaz seramikle kaplanması, alanda 5 adet $100 \mathrm{~cm} \times 80 \mathrm{~cm}$ boyutlarında aydınlatma pencerelerinin olması ve mahya boyunca $15 \mathrm{~cm}$ genişliğinde üzeri şapkayla örtülmüş doğal havalandırma açıklığının bırakılması öngörülmüştür. Buzağı ahırının her iki başında olmak üzere 100 $\mathrm{cm} \times 200 \mathrm{~cm}$ boyutlarında iki adet kapı planlanmıştır.

Kesif ve Kaba Yem Depoları: Mevcut kesif yem deposunun taban alanı $40 \mathrm{~m}^{2}$ yüksekliği de 2.6 m'dir. Dolayısıyla depolama kapasitesi $104 \mathrm{~m}^{3}$ 'tür. İşletmenin kesif yem depolama kapasitesi hesaplanırken Anonim (2007)'deki değerler dikkate alınmıştır. Bu bağlamda kesif yemin depolanması için gerekli hacim $18 \mathrm{~m}^{3}$ olarak hesaplanmıştır. Mevcut kesif yem deposunun hacminin $104 \mathrm{~m}^{3}$ olduğu göz önüne alınırsa ihtiyacın bir hayli üstünde bir depolama hacminin olduğu görülmektedir.

Kaba yem deposunun modernizasyon sonras1 sahip olmas1 gereken kapasite hesab1 yine Anonim (2007)'ye göre yapılmıştır. Kaba yemin gerekli depolama hacminin $203 \mathrm{~m}^{3}$ olduğu ve mevcut depolama hacminin yaklaşık $335 \mathrm{~m}^{3}$ olduğu da dikkate alındığında kaba yem deposunun işletmenin 6 aylık gereksinimini fazlasıyla depolayabilecek kapasiteye sahip olduğu görülmektedir.

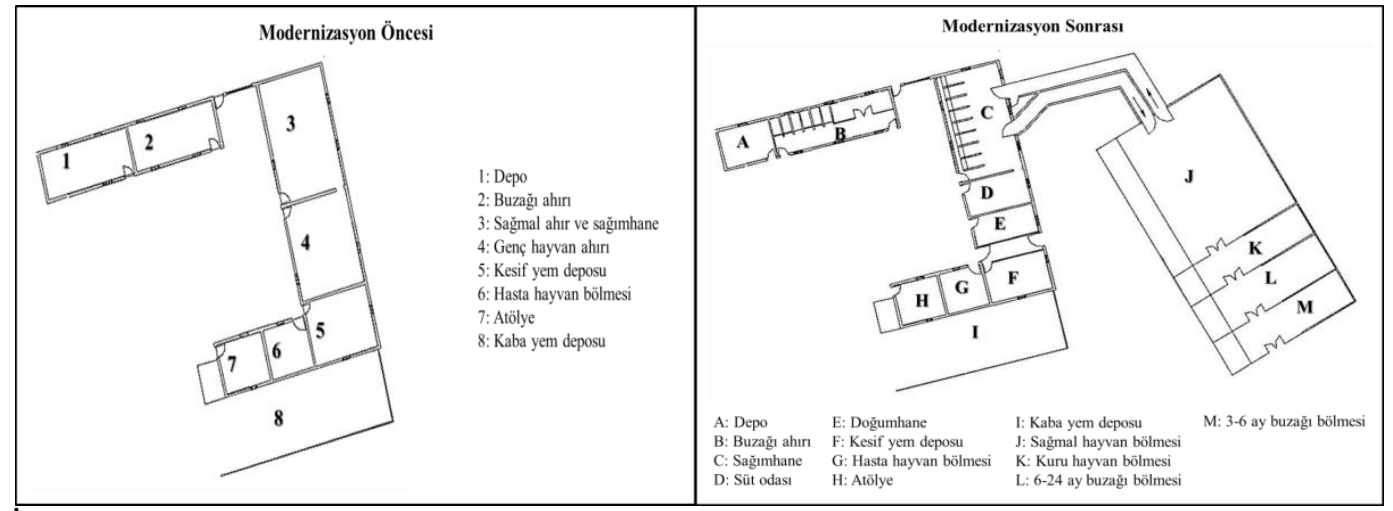

Şekil 2. Iş̧letme binalarının modernizasyon öncesi ve sonrası durumları

Yeni Tesis ve Binalar: Daha önce de açıklandığı üzere işletme sahibi hem daha modern bir sisteme sahip olmak hem de sahip olduğu bitişik araziyi kullanarak kapasitesini artırmak istemektedir. $\mathrm{Bu}$ bağlamda sağmal, genç ve kuruda hayvan ahırları söz konusu bitişik arazide yeniden projelendirilmiştir. Ayrıca gübre deposu da yeni projeye dahil edilmiştir. Gerek üreticinin talebi, gerekse de maliyeti azaltmak adına betonarme bir silaj ünitesi öngörülmemiştir. Silaj toprak üstü yığın şeklinde depolanacak, dolayısıyla herhangi bir yapıya gereksinim duyulmayacaktır.

Yeni Sağmal Ahır: Yeni sağmal ahır planlanırken projelenecek barınak içinde sağmal hayvanlarla birlikte kurudaki hayvanlar, 3-6 ay ve 6-24 aylık genç hayvanlara da alan bırakılması öngörülmüştür. Öncelikle eldeki arazi ve diğer imkanlar da dikkate alınarak işletmede barındırılabilecek maksimum hayvan sayılarının yani sürü kompozisyonun belirlenmesi gerekmektedir. Sürü kompozisyonu belirlenirken 20 sağmal hayvandan yola çıkılarak buzağı ve genç hayvan sayıları belirlenmiştir. Burada işletmenin ileriye yönelik genişleme imkanının bulunmaması dikkate alınarak şartlar oluşturulmuştur. İşletme sahibinin de görüşleri alınarak sürü kompozisyonu oluşturulmuştur. Buzağılama oranı \%80 olarak dikkate alınmış ve barındırılacak 0-3 aylık buzağı sayısının en çok 16 olabileceği hesaplanmıştır. Bu sayının yarısının erkek yarısının dişi olacağ dikkate alınırsa işletmede 0-3 aylık 8 dişi 8 erkek buzağı olacaktır. Üçüncü ay sonunda erkek buzağıların satılacağı kabul edilerek 3-6 aylık buzağı sayısı 8 olarak belirlenmiştir. İşletme düve satışı yapmay1 planlamaktadır dolayısıyla 6-24 ay yaş grubunda 8 düve olacağı öngörülmüştür.

Buzağılar için alan gereksinimi hesaplanırken 0-2 aylık buzağıların bireysel bölmelerde, 2-3 aylık buzağıların grup bölmesinde, 3-6 aylık ve 6-24 aylık düvelerin ise genç hayvan ahırında yani yeni inşa edilecek barınakta barındırılacağı dikkate alınmıştır. Yalnız gerek modernize edilecek buzağı 
ahırındaki mevcut imkânlar, gerekse yeni yapılacak ahırdaki mevcut alan el verdiği ölçüde çok hayvan barındırılacak şekilde kullanılmıştır. Bu bağlamda dikkate alınan hayvan sayıları ve Olgun (2016)'a göre belirlenmiştir.Yeni sağmal ahır serbest ahır sisteminde planlanmıştır. Arazinin şekli ve mevcut binalarla konumu da dikkate alınarak serbest ahırın gezinme alanı güney-batı'ya bakacak şekilde konumlandırılmıştır. Yeni halinde sağımhane olarak kullanılacak üniteyle yeni sağmal ahır arasında sığırların sağıma gidiş dönüşlerinde trafiği düzenleyecek geçitler oluşturulmuştur. İşletmenin modernizasyon sonrası görünümü Şekil 3'te modellenmiştir.

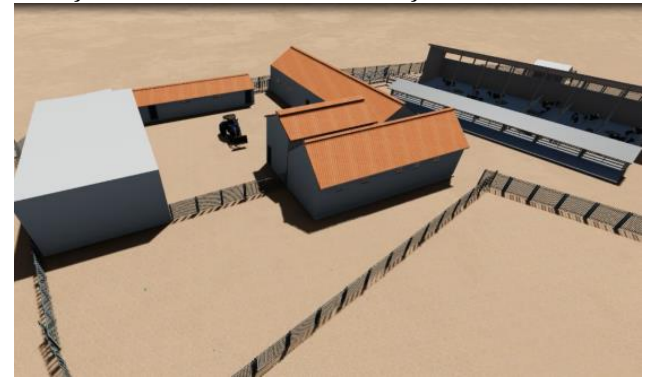

Şekil 3. İşletmenin modernizasyon sonrası 3 boyutlu modellemesi

Çelik Konstrüksiyon: Çelik konstrüksiyon yapı tasarlanırken daha önceden tespitleri yapılmış olan arazi yapsı, iklim koşulları, işletme sahibinin istekleri, hayvan isteklerinin optimum düzeyde tutulması, işetme kolaylığı gibi parametreler göz önünde bulundurularak en ekonomik şekilde tasarımın yapılmasına dikkat edilmiştir (Şekil 3). Tüm bu şartlar sonucunda ise hakim rüzgar yönünden gelecek olan zararlı hava akımını kesebilecek şekilde $706.42 \mathrm{~m}^{2}$ oturum alanına sahip kısmen açık ve serbest ahır sisteminde projelenmiştir.

Yapının tabanı dinlenme alanında; sıkıştırılmış zemin üstüne sıkıştırılmış dolgu malzemesi üstünde grobeton, gezinme alanında; sıkıştırılmış zemin üzerinde sıkıştırılmış dolgu malzemesi ve yemlenme alanında; sıkıştırılmış zemin üzerine sıkıştırılmış toprak üzerinde grobeton olacak şekilde tasarlanmıştır. Grobeton alanlar $\varphi$ 6.5'lik nervürlü hazır çelik hasır kullanılarak kuvvetlendirilmiştir. Ayrıca dinlenme alanlarındaki demir kolonlar için üst kotu beton seviyesinin $15 \mathrm{~cm}$ altında kalacak şekilde $80 \mathrm{~cm} \times 50 \mathrm{~cm}$ ebatlarında pabuçlar, demir direkler içine gömülecek şekilde tasarlanmıştır.

Hakim rüzgar yönünden gelecek olan zararlı hava akımını önlemek amacıyla bu yöndeki cephe $190 \mathrm{~mm} \times 135 \mathrm{~mm} \times 190 \mathrm{~mm}$ ebatlı yatay delikli tuğlalar üzerine çift yüzeye sıva olacak şekilde 3.25 m yükseklikte tasarlanmıştır.

Sera Tipi Ahır: Çelik konstrüksiyona alternatif olarak tasarlanan sera tipi sistem de arazi yapısı, iklim koşulları, işletme sahibinin istekleri, hayvan isteklerinin optimum düzeyde tutulması ve işletme kolaylığı gibi parametreler göz önüne alınarak $376.74 \mathrm{~m}^{2}$ oturum alanına sahip olacak şekilde projelendirilmiştir. Bu sistem, taşıyıcı olarak çelik kutu profilden oluşan kolonlar ve çelik borulu kemerler ile tasarlanmıştır. Tabanı sıkıştırılmış zemin üzerinde dolgu malzemesi ve üzerine grobeton olacak şekilde tasarlanmıştır. Hakim rüzgar yönünden gelen zararlı hava akımının kesilmesi ve grup bölmelerini oluşturmak amacıyla yapılacak olan duvarlarda yatay delikli tuğla kullanılmıştır. Çatı örtü malzemesi olarak polivinil örtü kullanılmış ve hakim rüzgar yönünde sadece saçak altında havalandırma açıklığı bırakılacak şekilde yan duvar tasarımı yapılmıştır (Şekil 4).

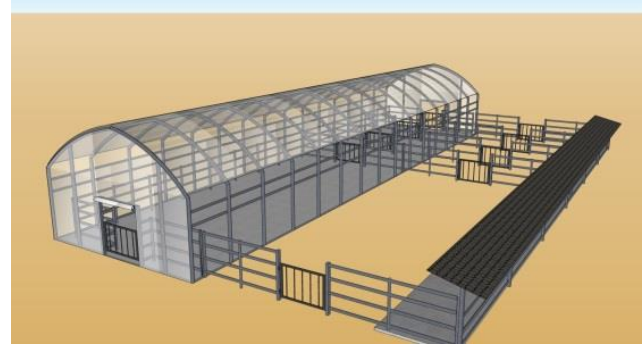

Şekil 4. Sera tipi ahır modellemesi

Gübre Deposu: İşletmede üretim boyunca ortaya çıkacak gübrenin depolanması amacıyla yine sundurma tipi çelik konstrüksiyon bir gübre deposu projelendirilmiştir. Deponun boyutlandırılmasında 
yeni ahır sisteminde barındırılacak hayvanların günlük gübre üretim kapasiteleri $50 \mathrm{~kg} / \mathrm{baş} \mathrm{olarak} \mathrm{ve}$ gübrenin birim hacim ağırlığı $975 \mathrm{~kg} / \mathrm{m}^{3}$ olarak dikkate alınmıştır.

\section{Sonuç ve Öneriler}

Küçük aile işletmeleri için modernizasyon genellikle durak sayılarının artırılması, başka bir yerde serbest duraklı bir ahır ve sağımhanenin inşa edilmesi şeklinde olmaktadır. İşletmelerin mevcut konumda genişlemeyi sağlayacak kadar arazisi olmayabilir. $\mathrm{Bu}$ durumda modernizasyon sadece mevcut yapıları kapsayacak ve yeni bina yapımına müsaade etmeyecektir. Bir diğer yaklaşımda aşamalı olarak modernizasyon çalışmalarını zamana yaymaktır (Mayer ve Kammel, 2010).

Modernizasyon çalışmasının bir parçası olarak değerlendirilebilecek sera tipi yapı sistemi özellikle Amerika Birleşik Devletlerinde kullanım alanı bulmuş bir alternatiftir. Bu bağlamda geleneksel çelik konstrüksiyon yapı sistemiyle birlikte sera tipi ahır sistemi de projelendirilip üreticiye alternatif olarak sunulmuştur.

Yıkım, onarım, kaplama, duvar, kapı ve pencere yapımı gibi işleri içeren modernizasyon çalışmalarının maliyeti 2019 yaz dönemi fiyatları dikkate alındığında 42,440.34 TL'ye mal olduğu görülmektedir. Metraj ve keşif çalışmasının yapıldığı dönemdeki kur yaklaşık olarak 5.70 \$/TL olarak dikkate alındığında modernizasyon çalışmasının bu işletme için maliyetinin 7,445.61 \$ olduğu görülmüştür. Proje uygulamaya geçtikten sonra sahip olunacak sağmal kapasitenin 20 olduğu düşünülürse sağmal hayvan başı maliyet 372.28 \$ olacaktır.

Sera tipi ve çelik konstrüksiyon sundurma tipi barınakların karşılaştırmasında sadece metraj sonucu elde edilen miktarların birim fiyatlarla çarpılması sonucu elde edilen işin keşif bedelleri esas alnımıştır. Çelik konstrüksiyon, sundurma tipi serbest ahır olarak projelendirilen yeni sağmal ahırın maliyetinin ise 109,592.71 TL olduğu görülmektedir. Yine döviz kuru dikkate alındığında bu rakam 19,226.79 \$ olarak hesaplanmıştır. Bu sistemin sağmal hayvan başına maliyetinin ise 961.35 \$ olduğu görülmüştür. Yine aynı kapasitede hayvan barındıracak olan sera tipi sistemin maliyeti 89,857.87 TL olarak hesaplanmış ve aynı kur dikkate alındığında 15,764.54 \$ olarak belirlenmiştir. Sağmal hayvan başına maliyetin ise 788.25 \$ olduğu görülmüştür. Her iki yapının metraj ve keşif özetleri Çizelge 1 ve 2 de verilmiştir.

Çizelge 1. Çelik konstrüksiyon ahır projesi maliyet çizelgesi

\begin{tabular}{|c|c|c|c|c|c|}
\hline Poz No & Tanımı & Birimi & $\begin{array}{c}\text { Birim } \\
\text { Fiyat (TL) }\end{array}$ & Metraj & $\begin{array}{l}\text { Toplam Tutar } \\
\text { (TL) }\end{array}$ \\
\hline Y.15.001/1A & $\begin{array}{l}\text { Makine ile yumuşak ve sert toprak kazılması } \\
\text { (serbest kazı) }\end{array}$ & $\mathrm{m}^{3}$ & 4.01 & 847.7 & $3,399.28$ \\
\hline Y.15.140/04 & $\begin{array}{l}\text { Çakıl temin edilerek, makine ile serme, } \\
\text { sulama ve sıkıştırma yapılması }\end{array}$ & $\mathrm{m}^{3}$ & 16.73 & 105.96 & $1,772.71$ \\
\hline Y.21.001/02 & $\begin{array}{l}\text { Ahşaptan düz yüzeyli beton ve betonarme } \\
\text { kalıb1 yapılması }\end{array}$ & $\mathrm{m}^{2}$ & 45.48 & 513.47 & $23,352.62$ \\
\hline Y.23.010 & $\begin{array}{l}\text { Nervürlü çelik hasırın yerine konulmas1 } \\
1,500-3,000 \mathrm{~kg} / \mathrm{m}^{2}\left(3,000 \mathrm{~kg} / \mathrm{m}^{2} \text { dahil }\right)\end{array}$ & ton & 3.616 .56 & 0.1335 & 482.81 \\
\hline Y.16.050/13 & $\begin{array}{l}\text { Beton santralinde üretilen veya satın alınan } \\
\text { ve beton pompasıyla basılan, C } 16 / 20 \text { basınç } \\
\text { dayanım sınıfında, gri renkte, normal hazır } \\
\text { beton dökülmesi (beton nakli dahil) }\end{array}$ & $\mathrm{m}^{3}$ & 174.65 & 77.02 & $13,451.54$ \\
\hline $04.016 / \mathrm{C} 02$ & $190 \times 135 \times 190 \mathrm{~mm}$ yatay delikli tuğla & $\mathrm{ad}$ & 0.34 & 5,782 & $1,965.88$ \\
\hline Y.27.501/04 & $\begin{array}{l}\text { 250/350 kg çimento dozlu kaba ve ince harçla } \\
\text { serpme (çarpma) sıva yapılmas }\end{array}$ & $\mathrm{m}^{2}$ & 22.06 & 413 & $9,110.78$ \\
\hline Y.27.501/02 & $\begin{array}{l}\text { 200/250 kg kireç/çimento karışımı kaba ve } \\
\text { ince harcla sıva yapılması (ic cephe sıvası) }\end{array}$ & $\mathrm{m}^{2}$ & 22.66 & 413 & $9,358.58$ \\
\hline 201.205 & $\begin{array}{l}\text { Dikişli galvanizli çelik boru 1" Ø } 25 \text { ortalama } \\
\text { dış çap } 33,7 / 3,25 \mathrm{~mm}\end{array}$ & $\mathrm{~m}$ & 16.70 & 384.60 & $6,422.82$ \\
\hline 201.208 & $\begin{array}{l}\text { Dikişli galvanizli çelik boru 2" Ø } 50 \text { ortalama } \\
\text { dış çap } 60,3 / 3,65 \mathrm{~mm}\end{array}$ & $\mathrm{~m}$ & 30.60 & 170.60 & $5,220.36$ \\
\hline 18.257 & $\begin{array}{l}\text { Çelik veya ön yapımlı betonarme kiriş } \\
\text { üzerine } 0.50 \mathrm{~mm} \text { kalınlıkta sıak daldırma } \\
\text { galvanizli oluklu/trapez sac ile çatı örtüsü } \\
\text { yapılması }\end{array}$ & $\mathrm{m}^{2}$ & 36.25 & 92.16 & $3,340.80$ \\
\hline
\end{tabular}




\begin{tabular}{|l|l|r|r|r|r|}
\hline Y.23.176 & $\begin{array}{l}\text { Lama ve profil demirlerden çeşitli demir } \\
\text { işleri yapıllması ve yerine konulması }\end{array}$ & $\mathrm{kg}$ & 9.56 & 85.38 & 816.23 \\
\hline ÖZEL-1 & $\begin{array}{l}\text { Proje ölçüleri dikkate alınarak her türlü } \\
\text { demir, çelik çatı ve taşıyıı sistemlerinin } \\
\text { yapılması }\end{array}$ & $\mathrm{m}^{2}$ & 105,00 & 259.02 & $27,197.10$ \\
\hline ÖZEL-2 & Otomatik hayvan suluğu & $\mathrm{ad}$ & 60.00 & 15 & 900.00 \\
\hline ÖZEL-3 & Su tesisatı & $\mathrm{ad}$ & 850.00 & 1 & 850.00 \\
\hline ÖZEL-4 & Elektrik tesisatı & $\mathrm{ad}$ & $1,350.00$ & 1 & $1,350.00$ \\
\hline & & \multicolumn{2}{|r|}{ TOPLAM (TL) } & $109,592.71$ \\
\hline
\end{tabular}

Çizelge 2. Çelik konstrüksiyon sera tipi sistem ahır projesi maliyet çizelgesi

\begin{tabular}{|c|c|c|c|c|c|}
\hline Poz No & Tanımı & Birimi & $\begin{array}{c}\text { Birim } \\
\text { Fiyat (TL) }\end{array}$ & Metraj & $\begin{array}{l}\text { Toplam Tutar } \\
\text { (TL) }\end{array}$ \\
\hline Y.15.001/1A & $\begin{array}{l}\text { Makine ile yumuşak ve sert toprak kazılması } \\
\text { (serbest kazı) }\end{array}$ & $\mathrm{m}^{3}$ & 4.01 & 910 & $3,649.10$ \\
\hline Y.15.140/04 & $\begin{array}{l}\text { Çakıl temin edilerek, makine ile serme, } \\
\text { sulama ve sıkıştırma yapılması }\end{array}$ & $\mathrm{m}^{3}$ & 16.73 & 136.50 & $2,283.65$ \\
\hline Y.21.001/02 & $\begin{array}{l}\text { Ahşaptan düz yüzeyli beton ve betonarme } \\
\text { kalıbı yapılması }\end{array}$ & $\mathrm{m}^{2}$ & 45.48 & 295.50 & $13,439.34$ \\
\hline Y.23.010 & $\begin{array}{l}\text { Nervürlü çelik hasırın yerine konulmas1 } \\
1,500-3,000 \mathrm{~kg} / \mathrm{m}^{2}\left(3,000 \mathrm{~kg} / \mathrm{m}^{2} \text { dahil }\right)\end{array}$ & Ton & $3,616.56$ & 0.08 & 289.32 \\
\hline Y.16.050/13 & $\begin{array}{l}\text { Beton santralinde üretilen veya satın alınan } \\
\text { ve beton pompasıla basılan, C } 16 / 20 \text { basınç } \\
\text { dayanım sınıfında, gri renkte, normal hazır } \\
\text { beton dökülmesi (beton nakli dahil) }\end{array}$ & $\mathrm{m}^{3}$ & 174.65 & 44.33 & $7,742.23$ \\
\hline 201.208 & $\begin{array}{l}\text { Dikişli galvanizli çelik boru 2" Ø } 50 \text { ortalama } \\
\text { diş çap } 60,3 / 3,65 \mathrm{~mm}\end{array}$ & $\mathrm{~m}$ & 30.60 & 481.20 & $14,724.72$ \\
\hline 201.205 & $\begin{array}{l}\text { Dikişli galvanizli çelik boru 1" Ø } 25 \text { ortalama } \\
\text { diş çap } 33,7 / 3,25 \mathrm{~mm}\end{array}$ & $\mathrm{~m}$ & 16.70 & 792.20 & $12,177.64$ \\
\hline 18.257 & $\begin{array}{l}\text { Çelik veya ön yapımlı betonarme kiriş } \\
\text { üzerine } 0.50 \mathrm{~mm} \text { kalınlıkta sicak daldırma } \\
\text { galvanizli oluklu/trapez sac ile çatı örtüsü } \\
\text { yapılması }\end{array}$ & $\mathrm{m}^{2}$ & 36.25 & 92.16 & $3,340.80$ \\
\hline Y.23.176 & $\begin{array}{l}\text { Lama ve profil demirlerden çeşitli demir } \\
\text { işleri yapılması ve yerine konulması }\end{array}$ & $\mathrm{kg}$ & 9.56 & 85.38 & 816.23 \\
\hline $04.278 / 3 \mathrm{~F}$ & Galvaniz tel & $\mathrm{kg}$ & 3.45 & 70.34 & 242.67 \\
\hline ÖZEL-1 & $\begin{array}{l}\text { Polivinl kaplama malzemesi ile her türlü } \\
\text { kaplama yapılması }\end{array}$ & $\mathrm{m}^{2}$ & 65.00 & 403.70 & $26,240.50$ \\
\hline ÖZEL-2 & Civata ve somun & $\mathrm{ad}$ & 0.85 & 300 & 255.00 \\
\hline ÖZEL-3 & Otomatik hayvan suluğu & $\mathrm{ad}$ & 60.00 & 15 & 900.00 \\
\hline ÖZEL-3 & Su tesisat 1 & $\mathrm{ad}$ & 850.00 & 1 & 850.00 \\
\hline ÖZEL-4 & Elektrik tesisat1 & $\mathrm{ad}$ & $1,350.00$ & 1 & $1,350.00$ \\
\hline \multicolumn{5}{|c|}{ TOPLAM (TL) } & $89,857.87$ \\
\hline \multicolumn{5}{|c|}{ TOPLAM (\$) } & $15,764.54$ \\
\hline
\end{tabular}

Sadece yeni ahır maliyetleri dikkate alındığında sera tipi sistem olarak yapılan aynı boyutlardaki ahırın geleneksel çelik konstrüksiyon ahıra göre yaklaşık olarak \%16 daha ucuza mal edildiği görülmektedir. Gübre deposunun maliyeti $6,968.76$ TL ya da dolar kuru dikkate alındığında 1,222.59 \$ olarak belirlenmiştir. Sağmal hayvan başına maliyetin 61.13 \$ olduğu görülmektedir.

Bütün maliyetler (modernizasyon ve yeni binalar) dikkate alındığında projenin genel keşif bedeli geleneksel çelik konstrüksiyon sistem için 159,001.81 TL (27,895.05 \$) olarak hesaplanmıştır. Nihai sağmal kapasitesi olan 20 baş dikkate alındığında ise sağmal hayvan başına düşen maliyet 1,394.75 \$/sağmal olmaktadır. Benzer şekilde toplam maliyetin sera tipi sistem için 139,266.97 TL $(24,432.80$ \$) olduğu görülmüştür. Bu maliyetin sağmal hayvan başına bedeli ise 1,221.64 \$/sağmal olarak karşımıza çıkmaktadır. Projenin genel toplam maliyetleri dikkate alındığında sera tipi sistemin uygulanması koşulunda keşif bedelinin yaklaşık olarak \%13 kadar daha ucuza mal edileceği görülmektedir. 
Yaslıoğlu (2004) yaptığı bir çalışmada Bursa İlinde 20 ve 50 baş sağmal kapasiteli 2 ayrı süt sığırı işletmesi projelendirmiş ve maliyetleri sırasıyla 2,800 ve 2,100 \$/sağmal olarak belirlemiştir. Görüldüğü üzere 20 baş kapasite dikkate alındığında bizim modernizasyon çalışmamızda sağmal başına geleneksel ve sera tipi yapı sistemleri için maliyet sırasıly $1,394.75$ ve $1,221.64$ \$ olarak hesaplanmıştır. Yine aynı araştırmacı 20 başlık işletme için modernizasyon maliyetinin yeniden inşa maliyetine oranını 0.44 olarak hesaplamıştır. Yirmi baş sağmala sahip bir işletmenin yeniden inşa maliyetinin 2,800 \$/sağmal olduğu dikkate alınırsa bu oran bizim çalışmamızda geleneksel çelik konstrüksiyon ve sera tipi sistem için sırasıyla 0.47 ve 0.43 olarak karşımıza çıkmaktadır. Bu değerler ise Yaslığlu (2004) ile uyum göstermektedir.

$\mathrm{Bu}$ sonuçlar dikkate alındığında ülkemiz koşullarında küçük aile işletmelerinin modernizasyonu ile barınak maliyetlerinde yaklaşı \%50'lik tasarruf sağlamak mümkün olabilmektedir. Sağmal hayvan sayısının artması durumunda bu rakamın daha da artacağı yine Yaslıoğlu (2004)'e göre açıktır. Dolayısıyla modernizasyon çalışmalarının faydalarının hem üreticilerle hem de ilgili kurumların yetkilileriyle paylaşılması gerekmektedir.

Ayrıca, geleneksel çelik konstrüksiyon sistem ile sera tipi sistem kıyaslandığında bina maliyetinin 20 baş sağmal hayvan için sera tipi sistemde yaklaşı $\% 16$ daha ucuz olarak bulunması ekonomik olarak olumlu olarak görülmektedir. Ancak sera tipi sistemin kesinlikle bir alternatif olarak önerilebilmesi için daha fazla çalışmaya ve veriye ihtiyaç bulunmaktadır. Elde edilen bu rakam ve sistemin ülkemizde uygulamasının nerdeyse hiç olmadığı dikkate alınırsa sera tipi sistemin kesinlikle önerilmesi için henüz erken olduğu ortaya çıkmaktadır.

\section{Kaynaklar}

Anonim, 2007. Kooperatif Projelerinde Müşterek Üretim Ünitelerinin Yapımında Uyulacak Esaslar. Tarım ve Köy İşleri Bakanlığı, Teşkilatlanma ve Destekleme Genel Müdürlüğü Genelgesi No:2007/9, Ankara.

Connor, M.L., 1993. Biotech shelters. Alternative housing for feeder pigs. Manitoba Swine Seminar Proc. 7:81.

Doran, B., Euken, R., Spiehs, M., 2010. Hoops and mono-slopes: what we have learned about management and performance. In Feedlot Forum 2010. Ames, Iowa: Iowa State University, Iowa Beef Center.

Esmay, M.L., 1978. Principles of animal environment. AVI Publishing Company. Westport, Connecticut.

Herbut, P., Nawalany, G., Angrecka, S., Sokołowski, P., Godyń, D., 2017. A technical analysis of barns on large dairy farms in northern poland. Nr II/2/2017, Polska Akademia Nauk, Oddział w Krakowie. 837-847.

Honeyman, M.S., 2005. Extensive bedded indoor and outdoor pig production systems in USA: current trends and effects on animal care and product quality. Livestock Production Science. 94:15-24.

Honeyman, M.S., Harmon, J.D., Kliebenstein, J.B., Richard, T.L., 2001. Feasibility of hoop structures for market swine in Iowa: pig performance, pig environment, and budget analysis. Applied Engineering in Agriculture. 17(6): 869-874.

Honeyman, M.S., Harmon, J.D., Shouse, S.C., Busby, W.D., Maxwell, D.L., 2008. Feasibility of bedded hoop barns for market beef cattle in Iowa: cattle performance, bedding use, and environment. Applied Engineering in Agriculture. 24(2): 251-256.

Horne, P., van Prins, H., 2002. Development of dairy farming in the Netherlands in the period 1960-2000. The Hague, Agricultural Economics Research Institute (LEI), 2002 Report 2.02.07; ISBN 90-5242-729-1 26 s.

Kammel, D., 2004. Hoop barns for dairy cattle. AED 51. MidWest Plan Service, Iowa State Univ., Ames.

Kızıl, Ü., Arıcı, İ., Şimşek, E., Yaslıoğlu, E., 1998. Süt sığırlarında 1sı stresi ve 1sı stresine karşı alınabilecek önlemler. 1998 Ege Bölgesi 1. Tarım Kongresi Konferansı, Aydın. 2: 173-180.

Mayer, M.W., Kammel D.W., 2010. Dairy modernization works for family farms. Journal of Extension 48(5): 5RIB7 1-9.

Moody, L.B., Pederson, C., Burns, R. T., Khanijo, I., 2006. Vegetative treatment systems for open feedlot runoff: project design and monitoring methods for five commercial beef feedlots. Paper No. 064145, ASABE., St. Joseph, MI.

Olgun, M., 2016. Tarımsal yapılar (Üçüncü Baskı). Ankara Üniversitesi Ziraat Fakültesi Yayın No:1577, Ders Kitabı:529, 445 s., Ankara.

Özdemir, M.Y., 2007. Tokat merkez ilçedeki süt sığııı ahırlarının yapısal ve çevre koşulları yönünden yeterliliklerinin ve geliştirme olanaklarının araştırılması. Yüksek Lisans Tezi. Gaziosmanpaşa Üniversitesi Fen Bilimleri Enstitüsü Tarımsal Yapılar ve Sulama Anabilim Dalı.

Uzundumlu, A.S., 2012. Tarım sektörünün ülke ekonomisindeki yeri ve önemi. Alınteri. 22(B): 34-44.

Woodbury, B. L., Nienaber J. A., Eigenberg R. A., 2002. Operational evaluation of a passive beef cattle feedlot runoff control and treatment system. App. Engr. In Agric. 18(5):541-545. 
ÇOMÜ Zir. Fak. Derg. (COMU J. Agric. Fac.)

2020: 8 (1): 11-19

ISSN: $2147-8384$ / e-ISSN: 2564-6826

doi: 10.33202/comuagri.603311

Yaslıoğlu, E., 2004. Damızlık süt sığırı işletmeciliğine uygun soğuk ahır tiplerinin geliştirilmesi üzerine bir araştırma. Doktora Tezi, Uludağ Üniversitesi, Tarımsal Yapılar ve Sulama ABD, Bursa.

Yaslığlu, E., Şimşek, E., Arıcı, İ., 2008. Renovation requirement for dairy cattle barns and two renovation models for existing dairy barns in Bursa. Journal of Agricultural Faculty of Uludag University. 22(1): 75-86.

Yılmaz, G., Kızıl, Ü., 2018. Küçük süt sığırı barınaklarının modernizasyonu ve Biga Örneği. 2. Uluslararası Mimarlık ve Tasarım Kongresi, Çanakkale, Türkiye. 758-766. 